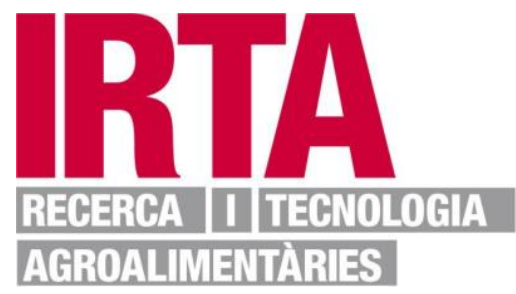

This is the peer reviewed version of the following article: Vilanova L.,Teixidó N.,Usall J., Balsells-Llauradó M, Gotor-Vila A.,Torres R. "Environmental Fate And Behaviour Of The Biocontrol Agent Bacillus Amyloliquefaciens CPA-8 After Preharvest Application To Stone Fruit. - Pubmed - NCBI". Wiley, which has been published in final form at https://www.ncbi.n/m.nih.gov/pubmed/28846195. This article may be used for non-commercial purposes in accordance with Wiley Terms and Conditions for Use of Self-Archived Versions 


\title{
Environmental fate and behaviour of the biocontrol agent Bacillus amyloliquefaciens CPA-8 after preharvest application to stone fruit
}

Authors: Laura Vilanova ${ }^{a}$, Neus Teixidó ${ }^{a}$, Josep Usall ${ }^{\mathrm{a}}$, Marta Balsells-Llauradóa

$$
\text { Amparo Gotor-Vila }{ }^{\mathrm{a}} \text {, Rosario Torres }{ }^{\mathrm{a}^{*}}
$$

Address:

${ }^{1}$ IRTA, XaRTA-Postharvest, Parc Científic i Tecnològic Agroalimentari de Lleida, Parc de Gardeny, Edifici Fruitcentre. 25003-Lleida, Catalonia, Spain.

\author{
*Corresponding author: Rosario Torres \\ Tel.: +34902789449 (ext.) \\ Fax: +34973238301 \\ E-mail: rosario.torres@irta.cat
}

\begin{abstract}
BACKGROUND: Bacillus amyloliquefaciens strain CPA-8 has been described as an effective biocontrol agent to control brown rot in stone fruit for both preharvest and postharvest applications. However, no information about the environmental fate and behaviour of this strain under field conditions is available.

RESULTS: The dispersion of the CPA-8 application was evaluated using watersensitive papers, and complete coverage was observed on the leaves of treated trees, while less than $1 \%$ of non-treated tree leaves had CPA-8. CPA- 8 persisted on the fruit of treated trees during preharvest and postharvest conditions, while a significant decrease on leaves and weeds was observed 21 days after treatment. On non-treated trees, CPA- 8 was detected on leaves until 180 days after treatment, and on weeds, the CPA-8 population was dependent on the distance from the treated trees. A high
\end{abstract}

This article has been accepted for publication and undergone full peer review but has not been through the copyediting, typesetting, pagination and proofreading process, which may lead to differences between this version and the Version of Record. Please cite this article as doi: $10.1002 / p s .4716$ 
persistence of CPA-8 was detected on inert materials, such as clothes and gloves worn by handlers and plastic harvesting boxes. More than $99 \%$ of the samples with a CPA-8 phenotype were confirmed as CPA-8 using PCR.

CONCLUSION: This work demonstrated a good distribution, persistence and adaptation of the CPA- 8 strain to field and postharvest conditions. Monitoring of dispersion and persistence is an excellent tool to determine the time of application and provides valuable information for registering issues.

Keywords: peach; biological control agent; antagonist; persistence; population dynamics; PCR 


\section{INTRODUCTION}

Monilinia spp. are the causal agents of brown rot in stone fruit and are responsible for economic losses during both, preharvest and postharvest. During favourable climatic conditions for disease development, these losses can reach up to $80 \%$ for more susceptible late-ripening varieties. ${ }^{1}$ Currently, the primary strategy to control this disease in stone fruit is based on the application of chemical fungicides combined with adequate cultural practices. $^{2}$ However, several currently used preharvest fungicides (such as piridinyl-ethyl benzamides, dicarboximides, and triazole-like compounds) will have limited availability in the coming decade due to either, resistance appearance and health and environmental risks, leading to serious challenges for growers to produce healthy fruit in a sustainable way. These concerns have promoted the development of alternative methods. Biological control is considered the most promising strategy to replace the use of chemical fungicides, and its efficiency has been demonstrated in a large number of studies over the last 20 years. $^{3}$

Many Bacillus spp. have been reported as effective biological control agents (BCAs) against different plant diseases caused by soil borne, ${ }^{4}$ foliar, ${ }^{5}$ and postharvest pathogens. ${ }^{6}$ In particular, Bacillus amyloliquefaciens strain CPA-8 (formerly $B$. subtilis), was demonstrated to be effective in controlling brown rot caused by Monilinia spp. alone or in combination with other postharvest treatments. ${ }^{7,8}$ Moreover, recent

studies revealed that applications of B. amyloliquefaciens during the preharvest of peaches and nectarines substantially reduced brown rot decay during postharvest (unpublished results).

One of the main difficulties in commercialising a BCA is the registration procedure established by the European Commission regulation $1107 / 2009,{ }^{9}$ which concerns the commercialisation of plant protection products. Particularly, the Annex II section 
establishes the procedures and criteria for the approval of active substances in which the fate, behaviour and persistence of the product in the intended environment are considered. Compliance with this regulation requires the development of monitoring methods that allow for the precise identification and quantification of the microorganisms at the strain level, ${ }^{10}$ since applied BCAs usually belong to the same species as members of the microbiota. ${ }^{11}$

Traditional methods for monitoring BCAs have been based on dilution plating methodologies using selective or semi-selective culture media. ${ }^{12}$ However, this methodology is arduous because it requires a high level of expertise to differentiate among other morphologically similar species. These limitations have been solved using more specific methodologies based on DNA amplification with strain specific primers. With regards to $B$. amyloliquefaciens CPA-8, two different molecular markers were developed for its detection and identification. ${ }^{13}$ In that work, a strain-specific genomic marker for CPA-8 was obtained from the RBAM 007760 gene, which is primarily involved in bacterial surface adhesion.

With this in mind, we established an easy and reliable methodology to study the fate and behaviour of the CPA-8 strain after its application to flat peaches under field conditions and during postharvest storage using a combination of conventional and PCR methodologies. Specifically, the objectives were (a) to evaluate the dispersion of the preharvest treatment, (b) to determine the air distribution of the CPA-8 cells, (c) to quantify the population of the CPA-8 strain on the surface of peaches, leaves and weeds from the treated and non-treated neighbour trees, (d) to determine the persistence of the CPA-8 strain on the personal protective equipment and motorised sprayer, and (e) to quantify the population of the CPA-8 strain on fruit during postharvest storage.

\section{MATERIALS AND METHODS}




\subsection{Biological control agent}

The B. amyloliquefaciens strain CPA- $8^{13}$ was obtained from the culture collection of the IRTA Centre (Lleida, Catalonia, Spain). This strain was initially isolated from the surface of a nectarine in an experimental orchard in Lleida (Catalonia, Spain) and was selected for its efficacy in controlling brown rot disease. ${ }^{7,8}$ Bacteria were cultured and formulated by fluid-bed spray-drying according to the work reported by Gotor-Vila et al. ${ }^{14}$

\subsection{Preharvest treatments in the field}

Field experiments were carried out in a flat peach cv. '796' commercial orchard located in Malpartit (Alpicat, Catalonia, Spain). The BCA CPA-8 was sprayed onto flat peaches 3 days before harvest, on the $7^{\text {th }}$ of July, 2016. A portable weather station was located inside the orchard for measuring temperature, relative humidity, wetness, and rate of precipitation and was connected to a data logger for data registration.

To prepare an adequate CPA- 8 concentration for the treatment, $40 \mathrm{~g}$ of dried cells $\left(9 \times 10^{9} \mathrm{cfu} \mathrm{g}^{-1}\right)$ were dissolved into $30 \mathrm{~L}$ of water to obtain a final adjusted concentration of $10^{7} \mathrm{cfu} \mathrm{mL}^{-1}$. Each tree was sprayed for $20 \mathrm{~s}$ (approximately $3 \mathrm{~L}$ ) using a motorised sprayer (Benza P30P 2R, Ordes, Spain) at 15 bars of pressure.

The experimental design for each replicate consisted of 1 treated $(\mathrm{t})$ and 3 non-treated trees (a, same row neighbour; b, same column in the next row neighbour; $\mathrm{c}$, diagonal in the next row neighbour) and 3 replicates were evaluated (Fig. 1A). Each replicate was separated by 3 non-treated trees. Both treated and non-treated trees were used to monitor the dispersion, environmental distribution and the persistence of the CPA-8 preharvest treatment under field conditions. The sampling times were at $0 \mathrm{~h}$ (after letting the treatment dry) and at 1, 3 (fruit harvest for postharvest storage), 7, 14, 21, 28, $45,60,90,120,150$ and 180 days after treatment. The last sampling time was in December when the leaves had already fallen. 


\subsection{Monitoring the dispersion and the aerial distribution of the CPA-8 preharvest treatment in the field}

The dispersion of the CPA- 8 treatment was monitored on the leaves and on the orchard floor using water-sensitive papers (WSPs, Singenta, Madrid, Spain) (Fig. 1B). The WSPs were positioned on the leaves of the outside and inside canopies of the treated and non-treated trees using a doubled-sided adhesive tape. The WSPs on the ground were attached to a petri plate using doubled-sided adhesive tape and were placed around the treated ( 1 WSP in each vertex of the square of the treated tree, outside of the canopy) and non-treated trees ( 1 WSP in line with the treated tree, outside of the canopy, with another located at $1 / 2$ the distance between the canopy of the treated and non-treated trees). Once the WPSs were completely dried, they were stored in a plastic bag until further analysis. WSPs were scanned with a 600 dpi imaging resolution, and the percentage of the covered surface was estimated using the ImageJ Software (ImageJ, US National Institutes of Health, https://imagej.nih.gov/ij/) in combination with the macro developed by Gil et al. ${ }^{15}$

The aerial distribution and persistence were evaluated by gravimetry in the same points where the floor WSPs were located. Petri plates containing nutrient yeast dextrose agar (NYDA: $8 \mathrm{~g} \mathrm{~L}^{-1}$ nutrient broth, $5 \mathrm{~g} \mathrm{~L}^{-1}$ yeast extract, $10 \mathrm{~g} \mathrm{~L}^{-1}$ dextrose and $20 \mathrm{~g} \mathrm{~L}^{-1}$ agar) were left opened for $2 \mathrm{~min}$. Plates were incubated at $30{ }^{\circ} \mathrm{C}$ for $24 \mathrm{~h}$, and $10 \%$ of the total colonies from each plate that were phenotypically similar to Bacillus spp. were selected for PCR identification.

\subsection{Population dynamics of the CPA-8 preharvest treatment in treated trees}

The population dynamics of the CPA-8 treatment was quantified in different plant tissues of the treated trees, including the fruit, leaves and weeds. For the fruit, 5 fruits per replicate were harvested, and 8 pieces of peach peel (16 $\mathrm{mm}$ diameter) were 
removed with a cork borer from each fruit. These 40 pieces were dipped into $20 \mathrm{~mL}$ of phosphate buffer solution (0.05 $\mathrm{M}$ potassium phosphate, $\mathrm{pH} 6.5)$ in a sterile filter bag and were homogenised in a Stomacher (Seward, London, UK) set at 12 strokes s $^{-1}$ for $90 \mathrm{~s}$. For the leaves, 10 leaves were harvested, and two pieces from each $(19.6 \mathrm{~mm}$ diameter) were removed with a cork borer. These 20 pieces were dipped into $10 \mathrm{~mL}$ of phosphate buffer solution and homogenised in a Stomacher. For the weeds, 1 gram of weed was collected from two different sample points, dipped into $10 \mathrm{~mL}$ of phosphate buffer solution and homogenised in a Stomacher. For all plant tissues, serial ten-fold dilutions of suspension samples were made thrice by dilution plating on NYDA medium, which were incubated as described above. The results were expressed as cfu $\mathrm{cm}^{-2}$ or $\mathrm{cfu} \mathrm{g}^{-1}$ depending on the sample material. Two colonies were selected from each dilution plate for PCR confirmation.

\subsection{Persistence of the CPA-8 preharvest treatment in non-treated trees}

The persistence of the CPA-8 strain in non-treated trees (A, B and C) was evaluated in different plant tissues, including the fruit, leaves and weeds. The sampling method used to detect the CPA-8 strain in fruit and leaves was the contact plating method using Rodac (replicate organism direct agar contact) plates containing NYDA medium. For each sampling time and replicate, three Rodac plates were used for each tissue sampled. The colonies were incubated for enumeration and then were selected as follows: for Rodac plates, if the plate contained more than 10 colonies that were morphologically similar to Bacillus spp., $40 \%$ were selected for PCR confirmation. Otherwise, if the plate contained less than 10 colonies, all the colonies were confirmed by PCR.

The sampling method used to detect the CPA-8 strain in weeds from the non-treated trees was dilution plating, following the same protocol described previously for weeds 
of the treated trees. The plates were incubated for colony enumeration and were selected as described above for dilution plating.

\subsection{Population dynamics of the CPA-8 strain during postharvest storage}

The population dynamics of the CPA- 8 strain on the surface of flat peaches was quantified during postharvest storage $\left(0^{\circ} \mathrm{C}\right.$ and $85 \%$ relative humidity $\left.(\mathrm{RH})\right)$ at 7,15 , 21, 28 and 45 days after harvest. Moreover, the CPA-8 population was also quantified after simulating the shelf life period during the commercialisation process $\left(20^{\circ} \mathrm{C}\right.$ and 85 $\% \mathrm{RH}$ for 5 days after cold storage at 28 and 45 days). The population dynamics of CPA-8 on the fruit surfaces was determined by dilution plating, which, in addition to the number of colonies selected for confirmation by PCR, was done as previously described.

Moreover, the persistence of the CPA- 8 strain in the plastic boxes used to store fruit after harvest was also evaluated after $7,15,21,28$ and 45 days of storage at $0{ }^{\circ} \mathrm{C}$ and 85 $\%$ RH using Rodac plates as described above. At the end of the postharvest storage, the plastic boxes were cleaned by immersion for $30 \mathrm{~s}$ in a $5 \%$ soap water solution and were disinfected for $1 \mathrm{~min}$ in a $2 \%$ sodium hypochlorite water solution. Four days later, the same protocol was repeated but increasing the percentage of sodium hypochlorite up to $10 \%$. Once the plastic boxes were air dried, the persistence of the CPA- 8 was evaluated using the contact plating methodology. The colonies were incubated for enumeration and selected as previously described for contact plating methodology.

\subsection{Persistence of the CPA-8 preharvest treatment in the personal protective equipment (PPE) and in the motorised sprayer}

The persistence and survival of the CPA- 8 strain in the PPE of the treatment applicator was estimated on gloves and on the working clothes using the contact plating method with Rodac plates containing NYDA medium. Both right- and left-hand gloves were 
sampled, and the working clothes were sampled from both arms and legs, using two plates for the stomach and two plates for the back, totalling twelve Rodac plates for each sampling time. In the case of the motorised sprayer, five Rodac plates were used to detect the persistence of CPA-8 before and after treatment, and after cleaning the sprayer with water. The plates were incubated for colony enumeration as previously described for the contact plating methodology.

\subsection{Colony confirmation by PCR}

DNA from CPA-8 was extracted using physical methods. Colony samples $(2-5 \mathrm{mg})$ were introduced into a tube and were heated in the microwave at maximum voltage for $1 \mathrm{~min}$ and then cooled on ice for $5 \mathrm{~min}$. Samples were diluted with $20 \mu \mathrm{L}$ of molecular grade water (Fisher Scientific, Madrid, Spain).

To identify the CPA-8 strain, the primer pair RBAM007760F (GTACCGATTGCAACAGGTTTAGATG) and RBAM007760R (CTGTTGCCCCGG TTCGTC) described by Gotor-Vila et al. ${ }^{13}$ was used to amplify a 265 bp fragment. Each reaction had a final volume of $12.5 \mu \mathrm{L}$ and contained 1x Kapa 2G Robust Hot Start Ready Mix (Kapa Biosystems Inc., Wilmington, MA, USA), $500 \mathrm{nM}$ of each primer and $2 \mu \mathrm{L}$ of extracted DNA. The amplification was carried out in a GeneAmp PCR System 2700 (Applied biosystems, Madrid, Spain) thermal cycler following the cycling conditions described by Gotor-Vila et al. ${ }^{13}$ Two negative controls were used, one without DNA and the other with B. subtillis (Serenade, Bayer CropScience AG, Leverkusen, Germany), and one positive control with CPA-8. The PCR products were analysed by electrophoresis on a $1.2 \%$ agarose gel using a 100 bp DNA ladder (Nippon Genetics Europe, Dueren, Germany).

\subsection{Statistical analysis}


All data were analysed for significant differences using analysis of variance (ANOVA) with JMP V.8 (SAS Institute Inc.). Statistical significance was defined as $P<0.05$. When the analysis was statistically significant, t-test for two sample comparison or Tukey's test for the separation of means was performed.

\section{RESULTS}

\subsection{Meteorological data}

Meteorological data comprising the relative humidity $(\mathrm{RH})$, temperature $(\mathrm{T})$, wetness (W) and rainfall (R) are shown in Figure S1 (supplementary material) for the experimental period from $04 / 07 / 16$ to $12 / 12 / 16$. Specifically, July, August and September were characterised by a very warm and dry period $\left(\mathrm{T}\right.$ mean $=24.4^{\circ} \mathrm{C}$, $\mathrm{T}$ max $=39.3{ }^{\circ} \mathrm{C}$, RH mean $=57.1 \%$ and $\mathrm{RH} \min =22.9 \%$ ). Moreover, during these three months, it only rained four times, with a rainfall accumulation of $15 \mathrm{~mm}$ and a wetness accumulation of $16.6 \mathrm{~h}$ after raining. October was a warm month $\left(\mathrm{T}\right.$ mean $=16.2{ }^{\circ} \mathrm{C}, \mathrm{T}$ $\max =30.6{ }^{\circ} \mathrm{C}$, RH mean $=77.9 \%$ and $\mathrm{RH} \min =33.7 \%$, and during that time it rained five times with a rainfall of $31 \mathrm{~mm}$ and a subsequent wetness accumulation of 79.7 hours after raining. November and December were characterised by cold temperatures and high relative humidity $\left(\mathrm{T}\right.$ mean $=8.3{ }^{\circ} \mathrm{C}, \mathrm{T}$ min $=0.5^{\circ} \mathrm{C}$, $\mathrm{RH}$ mean $=$ $86.2 \%$ and $\mathrm{RH} \min =48.1 \%$ ). This high $\mathrm{RH}$ was accompanied with a high wetness accumulation (a total of $384 \mathrm{~h}$ during 1.5 months) mainly due to the presence of fog rather than rain accumulation $(54 \mathrm{~mm})$.

\subsection{Assessment of spray dispersion using water-sensitive papers}

The spray dispersion of the CPA-8 treatment was measured using WSPs located on the leaves (Fig. 2A) and on the ground (Fig. 2B). Significant differences were observed between the area covered from the papers located on the leaves from treated trees $(\mathrm{t})$ and on the leaves from the non-treated trees $(\mathrm{a}, \mathrm{b}$ or $\mathrm{c})$. While the application of the 
sprayed CPA-8 strain covered $100 \%$ of the surface of WSPs that were inside and outside of the canopy leaves of the treated trees, less than $1 \%$ of the area was covered in WSPs from the canopy leaves of the non-treated trees.

The dispersion of the CPA-8 treatment on the ground was represented as the relationship between the distance to the canopy of the treated and non-treated trees and the coverage area of the WSPs (Fig. 2B). It was observed that a larger area of the papers was covered for WSPs located at distances shorter than $0.5 \mathrm{~m}$, corresponding to the ground WSPs around the treated trees and the non-treated tree a. The WSPs located at a medium distance between the non-treated trees $\mathrm{b}$ and $\mathrm{c}$ showed a medium area of coverage (in a range of 1 to $38 \%$ ) while the WSPs located in the most distant area $(2.45$ m) showed less than $5 \%$ of area coverage.

\subsection{Aerial distribution of the CPA-8 strain at different distances to the canopy}

The aerial distribution of the CPA-8 strain was studied in relation to the application distance to the canopy and the sampling day after treatment (Fig. 3). Just after the application of the treatment $(0 \mathrm{~d})$, it was observed that CPA- 8 was distributed randomly around both the treated and non-treated trees, even at the farthest application distance to the canopy (non-treated tree $\mathrm{c}=2.45 \mathrm{~m}$ ). The general pattern observed over the next sampling days was similar, with a higher colony accumulation (the sum of all colonies ranged from 77 to 160 colonies plate ${ }^{-1}$ ) at distances shorter than $0.5 \mathrm{~m}$, corresponding to the area around the treated trees and the non-treated tree a. At greater distances, CPA- 8 colonies were also detected. In contrast, after 90 days of treatment it was observed a decrease in the number of aerial colonies at all checked distances. At distances shorter than $0.5 \mathrm{~m}$, a decrease in the number of aerial colonies was observed, from 28 colonies plate $^{-1}$ to just 1 colony plate ${ }^{-1}$ after 90 and 180 days after treatment, respectively. At distances greater than $0.5 \mathrm{~m}$, the decrease was from 22 colonies plate ${ }^{-1}$ ( 90 days after 
treatment) to 6 colonies plate ${ }^{-1}$ (150 days after treatment) (data not shown), and none was observed 180 days after treatment. It was remarkable that on the last sampling day (180 days after treatment) only one colony of CPA-8 was detected. Figures 4A and 4B show the phenotypic morphologies of CPA-8 colonies detected from air samples of treated and non-treated trees, respectively, and Figure 4C shows the PCR confirmation of these samples.

\subsection{Persistence of the CPA-8 strain on the treated trees}

The population dynamics of the CPA-8 strain on fruit, leaves and weeds of the treated trees were measured by dilution plating and confirmed by PCR (Figs. 5 and 6). Just after the preharvest application of the CPA- 8 treatment, the population level of the bacteria on fruit surfaces was $4.13 \log _{10} \mathrm{cfu} \mathrm{cm}^{-2}$ and remained stable for 3 and 45 days under field or postharvest conditions, respectively (Fig. 5). At postharvest, no statistical differences were observed between the population levels of CPA- 8 after 28 days at cold storage and 28 days at cold storage with a shelf life period of 5 days. However, a lower population of the CPA-8 strain was observed at 45 days at cold storage conditions (4.00 $\log _{10} \mathrm{cfu} \mathrm{cm}^{-2}$ ) in comparison to 45 days at cold storage with a shelf life period of 5 days $\left(4.24 \log _{10} \mathrm{cfu} \mathrm{cm}^{-2}\right)$.

The initial population of CPA-8 on leaves from the treated trees was $4.43 \log _{10} \mathrm{cfu} \mathrm{cm}^{-2}$, remaining stable until 21 days after treatment (Fig. 6). At this time, the population levels of the CPA-8 strain progressively decreased until 120 days after treatment $(1.88$ $\log _{10} \mathrm{cfu} \mathrm{cm}^{-2}$ ) and remained stable until the last sampling time after 180 days of the treatment $\left(1.68 \log _{10} \mathrm{cfu} \mathrm{cm}^{-2}\right)$.

In the case of the weeds, the initial population of CPA-8 was $6.26 \log _{10} \mathrm{cfu} \mathrm{g}^{-1}$ fresh weight $(\mathrm{FW})$ and remained stable until 21 days after treatment $\left(5.53 \log _{10} \mathrm{cfu} \mathrm{g}^{-1} \mathrm{FW}\right)$ (Fig. 6). Afterwards, the CPA-8 population decreased until $3.2 \log _{10} \mathrm{cfu} \mathrm{g}^{-1} \mathrm{FW}$, 
detected at 90 days after treatment. It is interesting to note the differences observed in the population levels among biological replications. This could be due to the presence of weeds at the beginning of the trials and the growth of new weeds over the timecourse of the sampling.

Figure 4A shows the phenotypic morphologies of CPA-8 colonies obtained from the leaves, fruit and weeds of treated-trees, and Figure 4C shows the PCR confirmation of these samples.

\subsection{Persistence of the CPA-8 strain on non-treated trees}

The persistence of the CPA-8 strain in the non-treated trees was evaluated using printings on fruit and leaves and by using dilution plating methodology for weeds. In fruit, after just 0 and 1 day of CPA-8 application, $89 \%$ of Rodac plates showed colonies that were phenotypically similar to CPA-8, which could be mostly confirmed (100 and $87 \%$, respectively) (Table 1). After 3, 7 and 15 days of treatment, $100 \%$ of sampled plates showed colonies that were phenotypically similar to CPA-8, and they were all confirmed as well. The persistence of CPA-8 on the surfaces of fruit under field conditions was probably longer than 15 days, however, no more sampling times were analysed due to the over-maturity of the fruit.

In leaves sampled up until 90 days after treatment, a general pattern was observed in which most of the Rodac plates yielded colonies that were morphologically similar to CPA-8, and they were all confirmed as the CPA-8 strain (Table 1). However, after 120 days, a decrease in the number of plates containing colonies similar to CPA-8 was observed, which was even more pronounced 180 days after the CPA- 8 treatment (when only one of the plates showed the presence of colonies that were morphologically similar to CPA-8). It is noteworthy that all the colonies that were morphologically 
similar to CPA-8 were confirmed except one, which was sampled 15 days after the CPA-8 application

Regarding the population dynamics of the CPA- 8 strain on weeds from non-treated trees, the same tendency in the population levels during the time course of the different non-treated trees was observed. The population levels decreased 1 day after treatment, increased between 3 and 7 days after treatment and finally start falling again until being maintained during the last sampling times (15-28 days after treatment). However, probably due to the important differences between the biological replicates, no statistical differences in the population levels during the time course were observed. The initial population levels detected in the weeds of the non-treated tree a were higher $(6.10$ cfu $\left.\mathrm{g}^{-1} \mathrm{FW}\right)$ than those detected in the non-treated trees b and c (3.96 and $3.84 \mathrm{cfu}^{-1}$ FW, respectively). During the first sampling times (1-7 days after treatment) the population levels detected in the weeds of the non-treated tree a were also higher than those detected in $\mathrm{b}$ and $\mathrm{c}$ (data not shown).

Figure 4B shows the phenotypic morphologies of the CPA- 8 colonies detected from leaves, fruit and weeds of treated-trees, and Figure 4C shows the PCR confirmation of these samples.

\subsection{Persistence of the CPA-8 strain on the personal protective equipment, motorised sprayer and postharvest plastic boxes}

On the gloves and clothes worn by handlers, the CPA-8 strain was detected and confirmed on all the plates from the day of the treatment until the last sampling time (180 days after treatment) (data not shown). In the case of the motorised sprayer, CPA-8 was not detected before the treatment. However, once CPA- 8 was applied, it was detected and confirmed for all sampled plates. Similar results were obtained after washing the motorised sprayer with water. 
The CPA-8 strain was also detected and confirmed in all sampled plates from the plastic boxes that contained the fruit during postharvest storage $(7,15,21,28$ and 45 days at 0 ${ }^{\circ} \mathrm{C}$ and $85 \% \mathrm{RH}$ after treatment) (data not shown). Furthermore, while the disinfection of the plastic boxes with $2 \%$ sodium hypochlorite did not affect the presence of CPA- 8 , the re-disinfection with $10 \%$ sodium hypochlorite partially eliminated the presence of CPA-8 colonies in $66.7 \%$ of the total sampling plates. Seven days after the redisinfection, CPA-8 was not detected in any plastic boxes (data not shown).

\section{DISCUSSION}

The efficacy of the preharvest (unpublished data) and postharvest application of the BCA B. amyloliquefaciens CPA-8 to control brown rot in stone fruit has already been demonstrated..$^{7,8}$ However, to assure its efficacy after field treatment, it is necessary to know the ecological fitness of this bacterium, which is determined by the physical and microbiological environment. ${ }^{16}$ Monitoring the ecological fitness is necessary for registration procedures since it is required to determine its traceability, persistence and environmental impact. ${ }^{17}$ Different methodologies have been used to assess the ecological fitness of BCAs. Taking advantage of the PCR technique developed by Gotor-Vila et al. ${ }^{13}$ it was possible to distinguish CPA- 8 from the non-target microbiota. In this study, more than 1800 samples that were phenotypically similar to CPA-8 were analysed, and only 10 of them gave a negative result by PCR confirmation. These results demonstrated that the plate counting methodology was suitable for monitoring the CPA-8 strain primarily due to the characteristic colony morphology, thus making it difficult to confuse within the other microbiota. Moreover, the fast growth of CPA-8 allowed incubation times of just $24 \mathrm{~h}$.

The dispersion of the treatment is one of the most important factors to take into account, since a correct spray can improve the accuracy and the efficiency of the treatment, thus 
achieving a more uniform spray deposition and avoiding loss of product and environmental contamination. ${ }^{18}$ For this reason, it is also important to monitor the spray treatment in treated and non-treated areas. In this study, the sprayed area of the WSPs was $100 \%$ when they were located on leaves outside and inside of the canopy of treated trees, while less than $1 \%$ of the covered area was detected on leaves of non-treated trees. These results agreed with those obtained by Soto-Muñoz et al. ${ }^{19}$ in a sprayer application of the BCA P. agglomerans CPA-2 in a citrus fruit orchard, despite the different training systems. However, both results are quite different from that obtained when using a chemical fungicide to control fruit diseases caused by species such as Monilinia spp. Syngenta Crop Protection AG (Basel, Switzerland) recommends at least $50-70$ droplets $\mathrm{cm}^{-2} 20$ and that a total coverage area of approximately $15 \%$ should be enough for satisfactory fungicide applications. ${ }^{21}$ These important differences in area coverage observed between the biocontrol applications and chemical treatments could be related with the mode of action of each product. While most chemical fungicides are systemic, B. amyloliquefaciens CPA-8, as other BCAs, needs a high population and viability to effectively colonise the fruit surface..$^{22}$ In the case of the WSPs located on the floor, an inverse relationship was observed between the distance to the canopy and the area of coverage, as well as in the number of air colonies at different sampled times. Only just after the treatment was a high density of aerial colonies observed around all the treated and non-treated areas.

The population dynamics of the CPA-8 strain were evaluated at different time courses on the fruit, leaves and weeds of treated trees to observe the presence and persistence of this BCA on different plant tissues, and to evaluate its adaptation to field conditions. This study demonstrated that CPA-8 was able to maintain the same population level for 3 days under field conditions and for 45 days at postharvest storage conditions. Gotor- 
Vila et al. $^{23}$ demonstrated that CPA-8 is a microorganism highly adapted to high temperatures under in vitro conditions, with stable viability in stone fruit surface exposed to 0 and $20^{\circ} \mathrm{C}$ and different $\mathrm{RH}$ values $(85,60$ and $40 \%) .{ }^{22}$ Depending on the microorganism (bacteria, yeast or fungi) these environmental factors could affect the viability of the BCAs to a greater or lesser degree. This is the reason why many studies have been conducted based on the adaptation of the microorganisms to improve their efficacy. ${ }^{24,25}$

In the phyllosphere and in the weeds, the population levels of CPA-8 showed a high dependence on environmental conditions. This study determined that population levels of CPA-8 remained stable until 21 days after treatment and then started falling. Despite the leaf surface being characterised by low nutrient availability and high exposure to environmental conditions, ${ }^{11}$ CPA-8 maintained a stable population level of $1.68 \log _{10}$ cfu $\mathrm{cm}^{-2}$ until the fall of the leaves, 180 days after treatment. Some authors have correlated this decrease to the stressful environmental conditions that stimulate the entry in a viable, but unculturable bacterial state. ${ }^{16}$ In this study, the decrease in bacterial populations on leaves could be related to the rainfall events accompanied with lower temperatures, since it has been demonstrated that the first $20 \mathrm{~mm}$ of rain considerably reduced the population of the BCAs from the fruit surface 22,26 and even similar tendencies were observed in the reduction of chemical treatments on grapes and vine leaves due to rainfall. ${ }^{27}$

Although the sprayed treatment seemed not to be dispersed on the leaves from the nontreated trees, CPA-8 was detected on both leaves and fruit over all analysed sampling times. While small drops of the treatment were not detected in WSPs at long application distances, ${ }^{28}$ CPA- 8 could be most likely detected due to the small size of the bacteria. These results indicate the high dispersion of the CPA- 8 strain in the field and its 
efficient colonisation and adaptation on fruit and leaf surfaces. In the case of the weeds, the differences between the population levels detected in the non-treated tree a, were approximately 100-fold higher than the ones detected in the non-treated trees b or c.

The persistence of the CPA-8 strain in inert materials conveniently stored indoors, such as PPE (clothes and gloves) was detected until 180 days after treatment. It is known that Bacillus endospores are extremely persistent, being viable in soils for a long time. ${ }^{29}$ Wood et al. ${ }^{30}$ showed that B. subtilis was found on glass, wood, concrete and topsoil up to 56 days after inoculation, although the viability was reduced when these materials (except topsoil) were exposed to UV radiation. In this work, despite the high persistence of CPA-8, it was also found that the disinfection of postharvest plastic boxes with a 10 $\%$ of bleach solution for just for one minute significantly reduced the viability of this microorganism.

In conclusion, tools such as those here developed to monitor a specific strain are crucial for determining the persistence and durability of the BCA in the agroecosystem. The EC Regulation $1107 / 2009{ }^{9}$ as well as the report of the second OECD biopesticides steering group seminar (2011) on the fate in the environment of microbial control agents and their effects on non-target organisms, stated the following requirements for introducing a plant protection product to the market: it shall have no unacceptable effects on the environment, its fate and distribution in the environment have to be accurately described as well as its impact on biodiversity and the ecosystem, including the ongoing behavior of the non-target species. According to that, the present work focused on the fate and environmental behaviour of the BCA CPA-8. The results revealed the good adaptation of this strain to field and postharvest conditions for optimal management of Monilinia spp. Moreover, the ability of CPA-8 to spread from treated to non-treated trees was also demonstrated, thus allowing a better homogeneity of the treatment and colonisation of 
the habitat. This knowledge could be used in the near future to not only improve the BCA-based products applied but also to design more detailed protocols for the control of disease, thus permitting better adjustment of the treatment doses and calendar applications. As said by Berg ${ }^{31}$, compared to chemicals, microorganisms are safer, show reduced environmental damage and potentially smaller risk to human health, show much more targeted activity, are effective in small quantities, multiply themselves but are controlled by the plant as well as by the indigenous microbiota populations, decompose more quickly than conventional pesticides, the resistance development is reduced due to several mechanisms and can be used in conventional or integrated pest management systems. Taken together all data available for CPA-8 13, 14, 22, 23 and even though such considerations are prone to a wide array of interpretations, products based on CPA-8 are now in the last stage of their commercial development, ready to the registration process. The integration of these products into the usual cropping systems can be a promising strategy to achieve a high level of control of brown rot, thus contributing to the management of postharvest diseases in stone fruit in the framework of a sustainable and/or organic agriculture.

\section{Acknowledgements}

This research was supported by the European project BIOCOMES FP7-612713 and by the Catalan government (Generalitat de Catalunya) for the PhD grant 2014-FI-B00367 (Amparo M. Gotor). The authors also thank CERCA Program (Generalitat de Catalunya) and the technical support provided by Cèlia Sánchez and Oana Bercea.

\section{REFERENCES}

1. Usall J, Casals C, Sisquella M, Palou L and De Cal A, Alternative technologies to control postharvest diseases of stone fruits. Stewart Postharvest Rev 4(2):1-6 (2015). 
2. Sisquella M, Viñas I, Picouet P, Torres R and Usall J, Effect of host and Monilinia spp. variables on the efficacy of radio frequency treatment on peaches. Postharvest Biol Technol 87:6-12 (2014).

3. Wisniewski M, Droby S, Norelli J, Liu J and Schena L, Alternative management technologies for postharvest disease control: The journey from simplicity to complexity. Postharvest Biol Technol 122:3-10 (2016).

4. Pane C, Villecco D, Campanile F and Zaccardelli M, Novel strains of Bacillus, isolated from compost and compost-amended soils, as biological control agents against soil-borne phytopathogenic fungi. Biocontrol Sci Technol 22(12):1373-1388 (2012).

5. Romero D, De Vicente A, Zeriouh H, Cazorla FM, Fernández-Ortuño D, Torés JA and Pérez-García A, Evaluation of biological control agents for managing cucurbit powdery mildew on greenhouse-grown melon. Plant Pathol 56(6):976-986 (2007).

6. Gao HY, Xu XX, Dai YW and He HX, Isolation, identification and characterization of Bacillus subtilis CF-3, a bacterium from fermented bean curd for controlling postharvest diseases of peach fruit. Food Sci Technol Res 22(3):377-385 (2016).

7. Casals C, Elmer PAG, Viñas I, Teixidó N, Sisquella M and Usall J, The combination of curing with either chitosan or Bacillus subtilis CPA-8 to control brown rot infections caused by Monilinia fructicola. Postharvest Biol Technol 64:126-132 (2012).

8. Yánez-Mendizábal V, Usall J, Viñas I, Casals C, Marín S, Solsona C and Teixidó N, Potential of a new strain of Bacillus subtilis CPA-8 to control the major postharvest diseases of fruit. Biocontrol Sci Technol 21(4):409-426 (2011).

9.https://osha.europa.eu/en/legislation/directives/regulation-ec-no-1107-2009-plantprotection-products 
10. Alabouvette $\mathrm{C}$ and Cordier $\mathrm{C}$, Risks of microbial biocontrol agents and regulation: are they in balance?, in Regulation of Biological Control Agents, ed. by Ehlers RU, Springer Netherlands, Dordrecht, pp. 157-173 (2011).

11. Lindow SE and Brandl MT, Microbiology of the phyllosphere. Appl Environ Microbiol 69(4):1875-1883 (2003).

12. Narayanasamy $\mathrm{P}$, Biological management of diseases of crops. Volume 1: Characteristics of biological control agents, Progress in biological control. Springer Science+Business Media, Dordrecht, Netherlands, (2013).

13. Gotor-Vila A, Teixidó N, Usall J, Dashevskaya S and Torres R, Development of a SCAR marker and a strain-specific genomic marker for the detection of the biocontrol agent strain CPA-8 Bacillus amyloliquefaciens (formerly B. subtilis). Ann Appl Biol 169(2):248-256 (2016).

14. Gotor-Vila A, Usall J, Torres R, Solsona C and Teixidó N, Biocontrol products based on Bacillus amyloliquefaciens CPA-8 using fluid-bed spray-drying process to control postharvest brown rot in stone fruit. LWT- Food Sci Technol 82:274-282 (2017).

15. Gil E, Gallart M, Llorens J, Llop J, Bayer T and Carvalho C, Spray adjustments based on LWA concept in vineyard. Relationship between canopy and coverage for different application settings, in International Advances in Pesticide Application, pp. 25-32 (2016).

16. Pujol M, Badosa E and Montesinos E, Epiphytic fitness of a biological control agent of fire blight in apple and pear orchards under Mediterranean weather conditions. FEMS Microbiol Ecol 59(1):186-193 (2007).

17. Montesinos E, Development, registration and commercialization of microbial pesticides for plant protection. Int Microbiol 6(4):245-252 (2003). 
18. Marçal ARS and Cunha M, Image processing of artificial targets for automatic evaluation of spray quality. ASABE 51(3):811-821 (2008).

19. Soto-Muñoz L, Torres R, Usall J, Viñas I, Dashevskaya S and Teixidó N, Environmental monitoring of the biocontrol agent Pantoea agglomerans CPA-2 applied to citrus fruit at preharvest. Ann Appl Biol 167(2):250-261 (2015).

20. Zhu H, Salyani M and Fox RD, A portable scanning system for evaluation of spray deposit distribution. Comput Electron Agric 76(1):38-43 (2011).

21. Deveau J, Airblast 101. A handbook of best practices in airblast spraying, (2016).

22. Gotor-Vila A, Usall J, Torres R, Ramos C and Teixidó N, Environmental stress responses of the Bacillus amyloliquefaciens CPA-8-formulated products on nectarines and peaches. Sci Hortic 225:359-365 (2017).

23. Gotor-Vila A, Teixidó N, Sisquella M, Torres R and Usall J, Biological characterization of the biocontrol agent Bacillus amyloliquefaciens CPA-8: the effect of temperatura, $\mathrm{pH}$ and water activity on growth, susceptibility to antibiotics and detection of enterotoxigenic genes. Curr Microbiol in press (2017).

24. Calvo-Garrido C, Teixidó N, Roudet J, Viñas I, Usall J and Fermaud M, Biological control of Botrytis bunch rot in Atlantic climate vineyards with Candida sake CPA-1 and its survival under limiting conditions of temperature and humidity. Biol Control 79:24-35 (2014).

25. Pascual S, Rico JR, De Cal A and Melgarejo P, Ecophysiological factors affecting growth, sporulation and survival of the biocontrol agent Penicillium oxalicum. Mycopathologia 139(1):43-50 (1997). 
26. Calvo-Garrido C, Viñas I, Usall J, Rodríguez-Romera M, Ramos MC and Teixidó N, Survival of the biological control agent Candida sake CPA-1 on grapes under the influence of abiotic factors. J Appl Microbiol 117(3):800-811 (2014).

27. Cabras P, Angioni A, Garau VL, Melis M, Pirisi FM, Cabitza F and Pala M, The effect of simulated rain on folpet and mancozeb residues on grapes and on vine leaves. J Environ Sci Health B 36(5):609-618 (2001).

28. Salyani M, Zhu H, Sweeb RD and Pai N, Assessment of spray distribution with water-sensitive paper. Agricultural Engineering International: GIGR Journal 15:101$111(2013)$.

29. Nicholson WL, Munakata N, Horneck G, Melosh HJ and Setlow P, Resistance of Bacillus endospores to extreme terrestrial and extraterrestrial environments. Microbiol Mol Biol Rev 64(3):548-572 (2000).

30. Wood JP, Meyer KM, Kelly TJ, Choi YW, Rogers JV, Riggs KB and Willenberg ZJ, Environmental persistence of Bacillus anthracis and Bacillus subtilis spores. PLoS One 10(9):e0138083 (2015).

31. Berg, G. Plant-microbe interactions promoting plant growth and health: perspectives for controlled use of microorganims in agriculture. J Appl Microbiol Biotechnol 84: 11-18 (2017). 
Fig. 2. Percentage area coverage with CPA-8 spray treatment obtained from the analysis of water sensitive papers (WSPs) using Image J Program. The WSPs were located (A) on the leaves of the outside and inside canopy of treated and non-treated trees and (B) on the ground around the treated and non-treated trees at different distances. Different letters indicate significant differences using Tukey's test $(P<0.05)$.

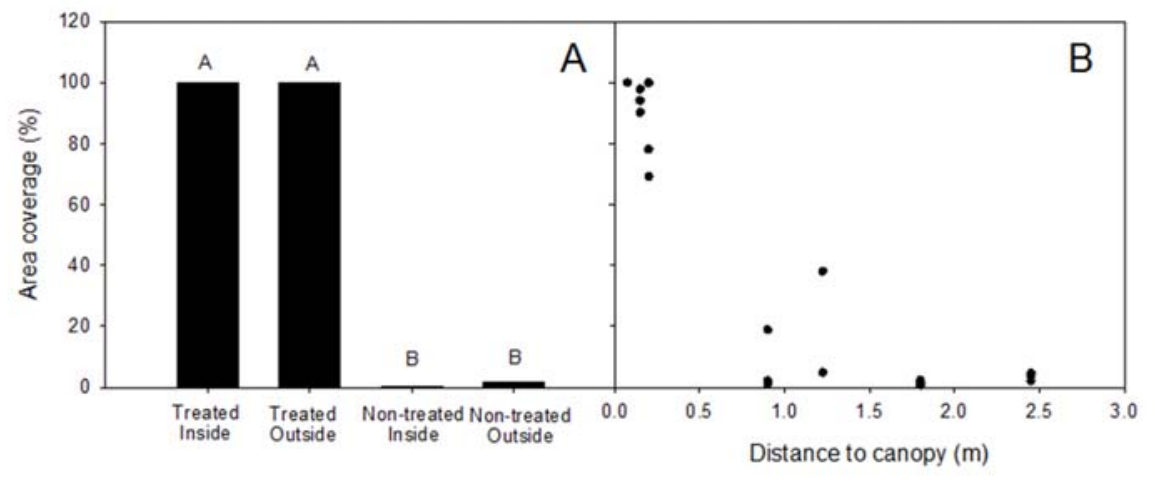

$$
\begin{aligned}
& \text { Figure } 2 . \\
& \text { Vilanova et al. }
\end{aligned}
$$

Fig. 3. Quantification of aerial colonies of the CPA-8 in relation to the distance to the canopy of the treated and non-treated trees at different times after treatment (AT). Colonies were quantified using the gravimetric methodology and colonies morphologically similar to Bacillus amyloliquefaciens were selected for CPA-8 confirmation. 

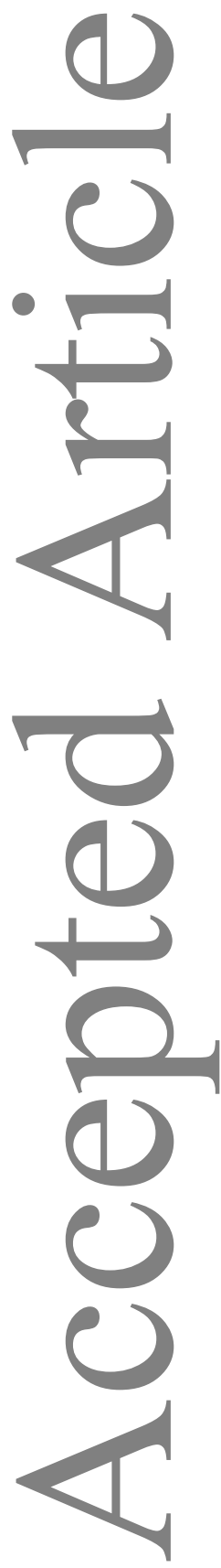

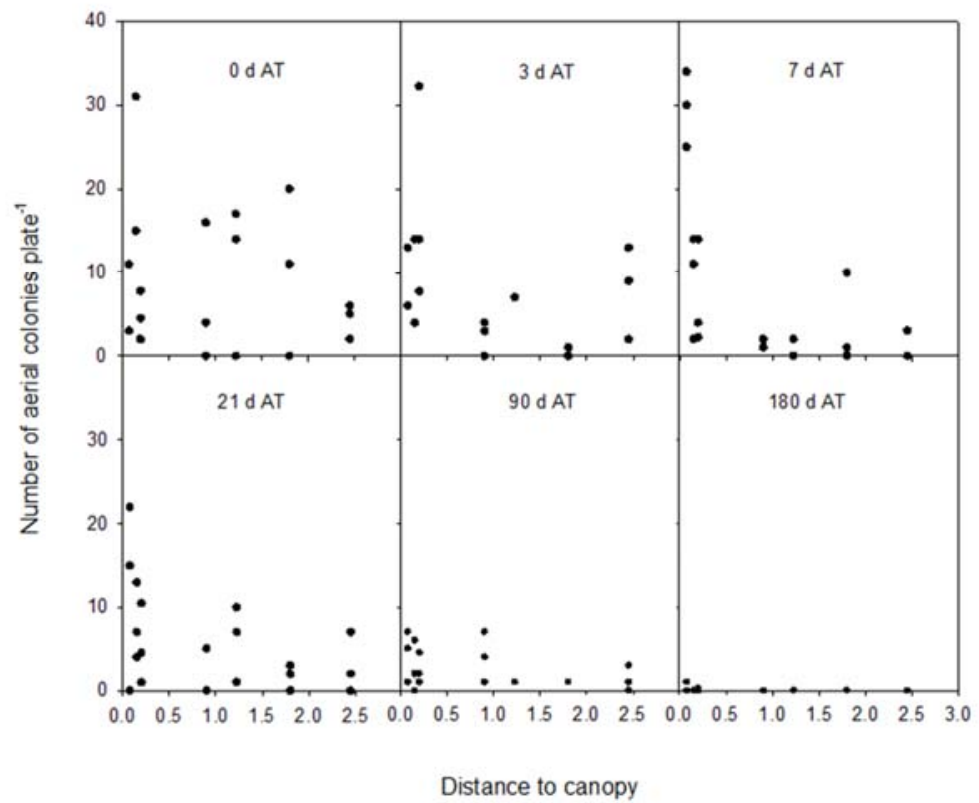

Figure 3.

Vilanova et al.

Fig. 4. Plate sampling from air, leaves, fruit and weeds from (1) treated and (2) nontreated trees that showed the presence of colonies morphologically similar to Bacillus amyloliquefaciens. (3) Example of sample confirmation as CPA-8 by polymerase chain reaction (PCR). 
A)

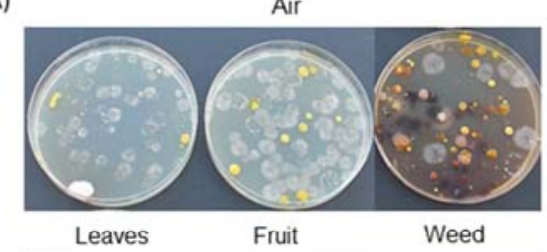

c)
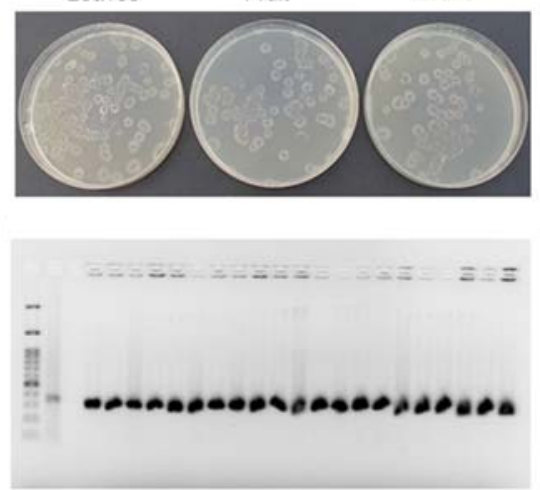

B)

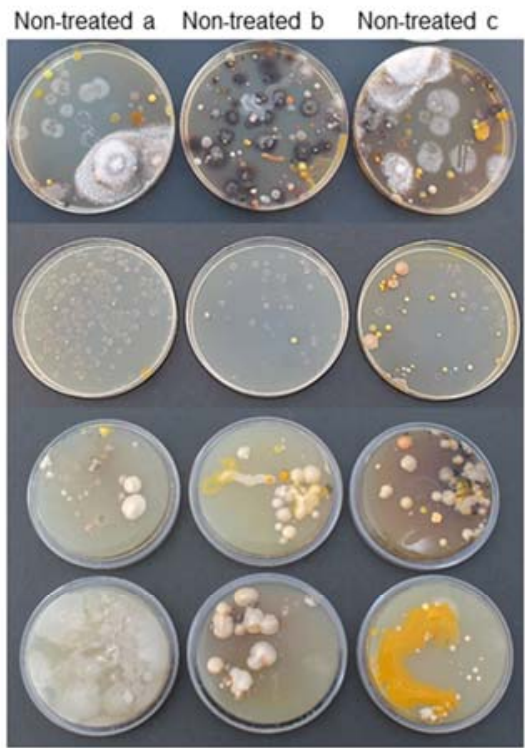

Figure 4.

Valanova et al.

Fig. 5. Population dynamics of CPA- 8 on flat peaches surface quantified by dilution plating and confirmed by PCR. The CPA- 8 treatment was sprayed 3 days before harvest (DBH). After harvest, fruit was stored at cold conditions $\left(0{ }^{\circ} \mathrm{C}\right.$ and $\left.85 \% \mathrm{RH}\right)$ for 7,15 , 21, 28 and 45 days. After 28 and 45 days of cold storage, fruit was exposed to $20{ }^{\circ} \mathrm{C}$ and $85 \mathrm{RH}$ for 5 days, simulating shelf life conditions. Each point represents the mean of three biological replicates and error bars represent the standard deviation of three biological replicates. ${ }^{*}$ indicates significant differences according to t-test $(P<0.05)$. 


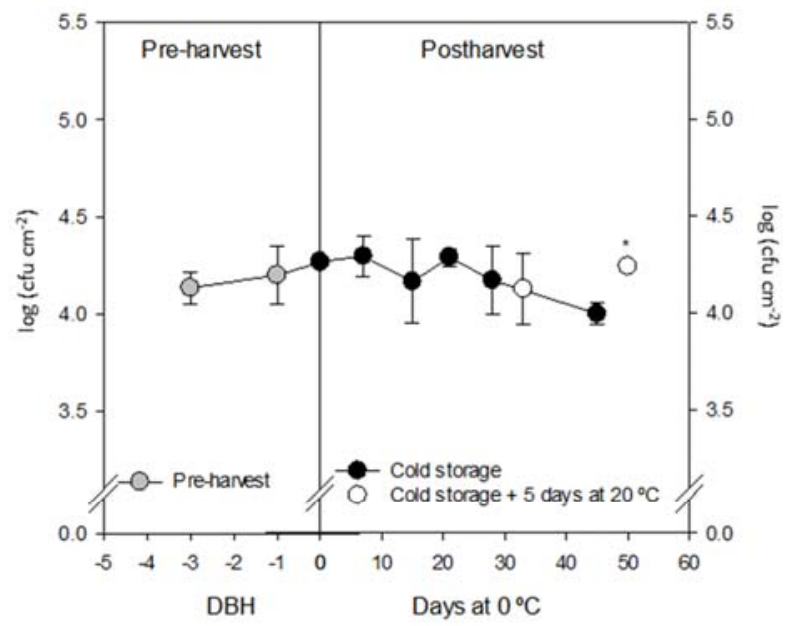

Figure 5.

Vianova et at.

Fig. 6. Population dynamics of CPA-8 on leaves $\left(\log \mathrm{cfu} \mathrm{cm}^{-2}\right)$ and weeds $\left(\log \mathrm{cfu} \mathrm{g}^{-1}\right.$ fresh weight) of the treated trees quantified by dilution plating and confirmed by PCR at different sampling times. Each point represents the mean of three biological replicates and error bars represent the standard deviation of three biological replicates. 
Table 1. Sampling plates from fruit and leaves of the non-treated area that showed similar phenotype to CPA-8 and that were confirmed as CPA- 8 using polymerase chain reaction (PCR).

\begin{tabular}{|c|c|c|c|c|c|}
\hline \multirow{2}{*}{$\begin{array}{l}\text { Plant } \\
\text { material }\end{array}$} & \multirow{2}{*}{$\begin{array}{l}\text { Days after } \\
\text { treatment }(\mathrm{d})\end{array}$} & \multicolumn{2}{|c|}{ Phenotypically similar to CPA- 8} & \multicolumn{2}{|c|}{ CPA-8 confirmed by PCR } \\
\hline & & Plate ratio $^{\mathrm{a}}$ & Percentage $(\%)$ & Plate ratio ${ }^{\mathrm{b}}$ & Percentage $(\%)$ \\
\hline \multirow{5}{*}{$\begin{array}{l}\text { Fruits } \\
(n=9)\end{array}$} & 0 & $8 / 9$ & 89 & $8 / 8$ & 100 \\
\hline & 1 & $8 / 9$ & 89 & $7 / 8$ & 87 \\
\hline & 3 (harvest) & $9 / 9$ & 100 & $9 / 9$ & 100 \\
\hline & 7 & $9 / 9$ & 100 & 9/9 & 100 \\
\hline & 15 & $9 / 9$ & 100 & $9 / 9$ & 100 \\
\hline \multirow{13}{*}{$\begin{array}{l}\text { Leaves } \\
(\mathrm{n}=9)\end{array}$} & 0 & $9 / 9$ & 100 & $9 / 9$ & 100 \\
\hline & 1 & $7 / 9$ & 78 & $7 / 7$ & 100 \\
\hline & 3 (harvest) & $9 / 9$ & 100 & $9 / 9$ & 100 \\
\hline & 7 & $9 / 9$ & 100 & $9 / 9$ & 100 \\
\hline & 15 & $9 / 9$ & 100 & $8 / 9$ & 89 \\
\hline & 21 & $9 / 9$ & 100 & $9 / 9$ & 100 \\
\hline & 28 & $9 / 9$ & 100 & $9 / 9$ & 100 \\
\hline & 45 & $9 / 9$ & 100 & $9 / 9$ & 100 \\
\hline & 60 & $9 / 9$ & 100 & $9 / 9$ & 100 \\
\hline & 90 & $9 / 9$ & 100 & $9 / 9$ & 100 \\
\hline & 120 & $6 / 9$ & 67 & $6 / 6$ & 100 \\
\hline & 150 & $7 / 9$ & 78 & $7 / 7$ & 100 \\
\hline & 180 & $1 / 9$ & 11 & $1 / 1$ & 100 \\
\hline
\end{tabular}

${ }^{a}$ Ratio of plate number with similar phenotype to CPA-8 in relation to the total number of sampled plates.

${ }^{\mathrm{b}}$ Ratio of plate number confirmed as CPA- 8 using PCR methodology in relation to the total number of sampled plates. 